\title{
INTEGRAÇÃO ENTRE GESTÃO DE PESSOAS E ESTRATÉGIA DE SUSTENTABILIDADE: O CASO NATURA
}

\author{
Fernanda Mendes Pires \\ Mestre em Administração de Empresas pela Universidade de São Paulo \\ fermpires@gmail.com \\ André Luiz Fischer \\ Professor na Universidade de São Paulo - FEA/USP \\ afischer@usp.br
}

\begin{abstract}
RESUMO
A crescente importância que a questão do desenvolvimento sustentável vem ganhando na sociedade e no debate acadêmico impulsiona as organizações a introduzi-la em suas estratégias e práticas de gestão. Esse tema vem tomando a agenda de executivos e das empresas, gerando um movimento que merece a reflexão da pesquisa organizacional. Este estudo busca contribuir com essa análise adotando a perspectiva da gestão estratégica de pessoas. Para compreender esse fenômeno, propõese verificar se ocorrem mudanças significativas nas políticas e práticas de gestão de pessoas das empresas que incorporam a sustentabilidade em sua estratégia de negócios. Para isso, realizou-se um estudo de caso em uma empresa reconhecida no Brasil por vincular sua imagem e estratégia de negócio com o desenvolvimento sustentável, a Natura. Políticas e práticas de $\mathrm{RH}$, tais como seleção, desempenho, remuneração e sucessão foram alinhadas à estratégia de sustentabilidade. A área de recursos humanos, bem como a liderança de toda empresa, é chamada a atuar como importante protagonista na busca por este posicionamento estratégico. Com isso, as três categorias identificadas na literatura - o papel da área de RH, a adaptação das políticas e práticas de RH e o papel dos líderes - puderam ser constatadas na pesquisa empírica.
\end{abstract}

Palavras-chave: Gestão de pessoas; Gestão estratégica de pessoas; Políticas e práticas de recursos humanos; Sustentabilidade.

\section{INTEGRATION BETWEEN PEOPLE MANAGEMENT AND SUSTAINABILITY STRATEGY: THE CASE NATURA}

\begin{abstract}
The growing importance of sustainable development concept in society and the academic debate propels organizations to introduce this concept into their strategies and management practices. Sustainable development has been taking the agenda of executives and companies, generating a need for reflection on organizational research. This paper investigates how Human Resource Management has incorporated significant changes by adopting business strategy focused on sustainability. This article also contributes to the analysis by investigating a recognized Brazilian sustainable company: Natura. The politics and practices of Natura, such as performance management, selection, compensation and succession, have aligned to the concept of sustainability. The Human Resources (HR) department, as well as leadership of every company, is required to act as a protagonist in the pursuit of strategic positioning. Thus, the three categories identified in literature - the role of HR, the adaptation of HR policies and practices and the role of leaders - could be found from the empirical research in the focused company.
\end{abstract}

Key words: Human resources policies and practices; sustainability; People management; Strategic people management. 


\section{INTRODUÇÃO}

O dilema do crescimento diante de uma economia baseada no consumo, os constantes questionamentos sociais em relação ao futuro da sociedade, o papel das empresas e dos indivíduos são fatores que impulsionam o movimento pelo desenvolvimento sustentável. O crescimento da discussão sobre o conceito estimula as organizações, grandes agentes da economia, a refletirem e questionarem sobre suas políticas e práticas de gestão. Trata-se de um movimento em crescimento e ainda, não institucionalizado na sociedade e nas organizações privadas. Senge, Smith, Kruschwitz, Schley e Laur (2009) afirmam que as organizações privadas são agentes relevantes desse movimento pela sustentabilidade, o que as tornam um importante objeto de investigação.

Diversos são os autores que sustentam a discussão teórica de sustentabilidade, tais como Gladwin, Kennelly e Krause (1995), Elkington (2001), Hart (2006), Savitz e Weber (2007) e Doppelt (2010), além de contribuições da literatura nacional: Oliveira (2008), Veiga (2010), Esteves (2009) e Abramovay (2010).

Muito se debate sobre o entendimento que cada empresa pode ter sobre o conceito de sustentabilidade e os diversos caminhos pelos quais poderá ser incorporada, a depender das lideranças e dos modelos de negócios empresariais. O que se vê na literatura, e também no ambiente empresarial, é que como não há modelos prontos, nem uma forma universal de pensar e incorporar o conceito, cada organização deve buscar uma maneira mais adequada a sua realidade.

Dessa forma, desafios estão colocados para as organizações que integram a sustentabilidade em sua gestão. Diversas são as dificuldades na inserção desse conceito e também na evolução dessa estratégia, o que inclui sua integração nas diferentes áreas da organização.

Partindo-se do pressuposto de que as empresas que inserem e valorizam a sustentabilidade em suas estratégias de negócio tendem a adaptar seus sistemas organizacionais a esse posicionamento, parece razoável supor que as políticas e práticas de RH desempenharão um importante papel em um processo de transformação organizacional.

Neste contexto, estudos internacionais, como os de Legge (2005), Ulrich (2000) e Boxall e Purcell (2008), discutem o papel de recursos humanos e as mudanças estratégicas das organizações. Para esses autores, a gestão de pessoas deve alinhar suas políticas e práticas de forma coerente aos objetivos empresariais.

Com vistas a contribuir com essa linha temática, este artigo se propõe a verificar se ocorrem mudanças significativas nas políticas e práticas de gestão de pessoas das empresas que incorporam a sustentabilidade em sua estratégia de negócios. A realização deste estudo foi motivada pela constatação de que, apesar da crescente preocupação com o desenvolvimento sustentável nas organizações, é reduzido o número de autores que analisam esse processo sob a perspectiva do Recursos Humanos.

Para sustentar esta discussão, realizou-se, também, um estudo da literatura que integra as duas frentes teóricas - sustentabilidade e recursos humanos - o que possibilitou a identificação de três focos prementes de preocupação dos autores: (1) mudanças quanto ao papel da área; (2) a integração da sustentabilidade na estratégia, políticas e práticas de gestão de pessoas; e, por fim, (3) a intervenção de RH junto aos líderes.

Para uma investigação empírica, a Natura tornou-se a empresa de foco para o estudo de caso. A coleta de dados envolveu observação, entrevistas e análise documental, que permitiu o levantamento de informações examinadas por meio de análise de conteúdo e dos resultados categorizados segundo os três focos teóricos identificados na literatura conjunta.

\section{FUNDAMENTAÇÃO TEÓRICA}

Para compor o referencial teórico optou-se por analisar inicialmente seus dois conceitos orientadores: o desenvolvimento sustentável e a gestão estratégica de pessoas. A seguir, procedeuse a uma análise sistemática da escassa literatura que relaciona estas duas temáticas. 


\subsection{Desenvolvimento sustentável e sustentabilidade nas organizações}

O desenvolvimento sustentável é um tema recente e abrangente para a sociedade, para as empresas e para a literatura. Segundo Veiga (2010), o debate deste movimento social exige um rompimento com a mentalidade da macroeconomia vigente, a compreensão dos limites naturais em relação às atividades econômicas e o fim da lógica social ancorada no aumento e na dependência do consumo. Para Barbieri, Vasconcelos, Andreassi e Vasconcelos (2010), trata-se de um dos movimentos sociais mais importantes do início deste século e milênio.

É comum definir-se como um marco importante na popularização deste conceito o ano de 1987, data em que a Comissão Mundial sobre Meio Ambiente e Desenvolvimento divulgou o Relatório de Brundtland, conhecido pelo título Nosso Futuro Comum. O relatório trouxe um conceito até hoje utilizado, que considera o desenvolvimento sustentável "[...] aquele que atende às necessidades do presente sem comprometer a possibilidade de as gerações futuras atenderem a suas próprias necessidades" (Cmmad, 1991, p. 46). O conceito propõe associar o crescimento econômico e o desenvolvimento social com a preservação ambiental.

É possível dizer que se trata de um conceito amplo e complexo, fruto de um debate relativamente recente, profundo e orientado por diversas definições. Além disso, a polêmica sobre como colocá-lo em prática está presente nas organizações e vem sendo debatido em diversos estudos acadêmicos.

Apesar disso, parece haver razoável grau de consenso sobre a efetividade do conceito do triple bottom line como orientador da gestão organizacional sustentável. Elkington (2001) defende a incorporação pela empresa de três pilares ou critérios de aferição dos seus objetivos: pessoas (people), planeta (planet) e lucro (profit). Essa perspectiva propõe que as organizações contribuam para a construção de um mundo capitalista sustentável, deixando de se orientar exclusivamente pelo lucro e incluindo em seus objetivos estratégicos também a sociedade e o cuidado com o ambiente das gerações futuras.

Adotando uma perspectiva crítica, Esteves (2009) demonstra que, no plano organizacional, o conceito tem acolhido diferentes significados, mas, se levada às últimas consequências, sua adoção pode mesmo questionar os próprios objetivos empresariais. Este é o motivo pelo qual o autor cunha o termo "sustentabilidade domesticada". Esta seria a forma mais comum de aplicação do conceito nas empresas, uma abordagem que não questiona a fundo o modelo empresarial e adota ações acomodadas à lógica vigente no sistema social dominante. Há que se constatar, porém, que, independentemente da vertente teórica do estudioso, a literatura admite a falta de consenso sobre o conceito, sua complexidade e as particularizações no que tange à sua adoção pelas organizações. (Faber, Jorna \& Engelen, 2005; Claro, Claro \& Amâncio, 2008; Savitz \& Weber, 2007; Hart, 2006). Nessa linha, Veiga (2010), discutindo as diferentes definições do conceito de sustentabilidade, lembra que noções importantes "[...]podem jamais ter definições suficientemente claras para que seu sentido venha a ser aceito por largo consenso" (2010, p. 13). Para o autor, a sustentabilidade, assim com a justiça, é um valor, decorre daí a dificuldade de tratá-la com uma definição precisa e capaz de ser facilmente operacionalizada.

O que parece ser mais tacitamente aceito é que a sustentabilidade apresenta-se em um território compartilhado pelos interesses das empresas e de diferentes públicos. Para os autores mais otimistas significa o repensar das estruturas de negócio, o que pode estimular uma transformação organizacional significativa ou, como querem alguns, de larga escala (Savitz \& Weber, 2007). Para os mais críticos, trata-se apenas de uma nova adaptação reativa e, muitas vezes, cosmética da empresa a uma demanda social emergente.

Entender melhor a efetividade e a autenticidade das empresas que se posicionam com negócios ligados a sustentabilidade certamente dependerá menos de uma posição teórica e ideológica prévia e mais de estudo de casos concretos. Somente por meio destes estudos empíricos será possível constatar se este posicionamento está trazendo resultados efetivos tanto para a empresa quanto para a sociedade na qual ela está inserida.

Revista de Gestão Social e Ambiental - RGSA, São Paulo, v. 8, n. 1, p. 54-72, jan./abr., 2014. 
São poucas, portanto, as áreas de consenso em torno desse tema, mas a maioria dos autores destaca a importância das pessoas na concretização de uma estratégia de sustentabilidade. Segundo Hart (2006), a integração da sustentabilidade à gestão organizacional ganha maior complexidade e efetividade quando interfere no comportamento das pessoas que atuam na organização. Para o autor, "[...]é pouco mais difícil - mas talvez mais importante - mudar a forma como as pessoas se comportam na companhia a partir dos processos que elas seguem" (p. 219). Como parece intuitivo concluir, somente pode-se dizer que uma organização coloca em prática uma estratégia de sustentabilidade se as pessoas que nela trabalham adotarem um comportamento alinhado com o conceito. Ganha atenção assim a gestão estratégica de recursos humanos, como principal sistema interno responsável por influenciar e direcionar o comportamento organizacional na Empresa alinhando-o com a sua estratégia de negócio.

\subsection{Gestão estratégica de pessoas}

É praticamente impossível falar de gestão de recursos humanos na atualidade sem se referir ao seu caráter estratégico. Um dos primeiros artigos com enfoque estratégico da gestão de pessoas foi publicado em 1981 (Wright, 1998) e, desde então diversos autores vêm tentando defender e demonstrar como RH se alinha (fit) e como contribui com a estratégia de negócio. É bem verdade que, no mundo da prática, as pesquisas constatam que o alinhamento entre gestão de pessoas e estratégia organizacional é ainda um grande desafio para a maioria das empresas (Lacombe \& Chu, 2008; Roehling et al. 2005; Lengnick-Hall, Lengnick-Hall, Andrade \& Drake, 2009).

Segundo Martín-Alcázar, Romero-Fernández e Sánchez-Gardey (2005, p. 651), a gestão estratégica de pessoas é "“[...]como um conjunto integrado de práticas, políticas e estratégias através das quais as organizações gerenciam seu capital humano, que influencia e é influenciado pela estratégia do negócio, o contexto organizacional e o contexto socioeconômico". Tal definição aponta a integração como importante aspecto dessa estratégia de RH e sua relação recursiva no contexto organizacional e socioeconômico.

Considerado um dos principais autores a respeito da gestão estratégica de RH, Ulrich (2000) defende um novo posicionamento para a área. $\mathrm{O}$ gestor de pessoas teria quatro papéis essenciais: especialista administrativo, defensor do funcionário, agente de mudança e parceiro estratégico. Estes dois últimos são os que mais interessam no contexto da gestão estratégica de RH e se aplicam aos objetivos deste estudo. Como gestor de mudanças, o RH deve capacitar a empresa a lidar com as transformações e tornar o empregado um ator desse processo. É fácil perceber como esse papel mostra-se relevante na internalização de uma estratégia voltada para a sustentabilidade. Como parceiro do negócio, Ulrich (2000) considera que o RH deve atuar para uma compreensão uniforme da estratégia dentro e fora da empresa, entre clientes e empregados, por exemplo, demonstrando clareza em relação aos objetivos empresariais.

No Brasil, Fleury e Fischer (1998) consideram importante o entendimento da gestão de pessoas além das fronteiras da própria área. Para as autoras, vista de forma sistêmica e estratégica, a gestão de pessoas pode ser "[...]compreendida como um conjunto de políticas e práticas definidas por uma organização para orientar o comportamento humano e as relações interpessoais no ambiente de trabalho" (p. 91).

Da mesma maneira, Lepak e Shaw (2008) consideram que esse sistema é formado por políticas e práticas cuja análise permite compreender a maneira pela qual a empresa contrata e gerencia seus empregados. As políticas e práticas demonstram também as formas como o trabalho é organizado dentro de uma empresa (Boxall \& Purcell, 2008), ou seja, se trata de um sistema que, ao mesmo tempo, representa o modo como a empresa pretende lidar com seus empregados e a forma como eles atuam.

Em que pesem as dificuldades que os pesquisadores constatam para as empresas promoverem um alinhamento efetivo entre a estratégia de negócio e a gestão de RH, é inegável que as organizações mais estruturadas nesse campo buscam essa coerência como uma espécie de alvo

Revista de Gestão Social e Ambiental - RGSA, São Paulo, v. 8, n. 1, p. 54-72, jan./abr., 2014. 
móvel. O discurso da gestão estratégica de pessoas está presente há mais de trinta anos na literatura e é bastante comum e disseminado entre os profissionais da área.

\subsection{A integração entre Gestão de Pessoas e Sustentabilidade}

Para formar a base de referência do estudo de caso que deu origem a este artigo foi realizado um levantamento da bibliografia que relacionava gestão de pessoas com sustentabilidade. Foram selecionados artigos que abordavam a principal questão de investigação desta pesquisa: mudanças nas políticas e práticas de $\mathrm{RH}$ decorrentes da estratégia de sustentabilidade. O levantamento, realizado em periódicos nacionais e internacionais, abrangeu dez anos, entre 2000 e 2010 , e resultou em dez artigos. A análise detalhada destes artigos demonstra que os autores identificaram três formas genéricas de integração de Recursos Humanos para uma estratégia de sustentabilidade: (1) mudanças quanto ao papel da área, que se tornou disseminadora deste novo posicionamento estratégico, contribuindo ativamente para a propagação de valores voltados para a sustentabilidade; (2) a integração da sustentabilidade na própria estratégia de gestão de pessoas ou, nas suas políticas e práticas; 3) a intervenção de RH junto aos líderes capacitando-os e orientando-os como disseminadores da sustentabilidade. Nos tópicos que se seguem será analisada cada uma dessas categorias.

\subsubsection{O papel da área de Gestão de Pessoas como agente de mudança estratégica e disseminadora de valores voltados para a sustentabilidade}

A maior parte da escassa literatura que analisa integradamente os dois temas, gestão de pessoas e sustentabilidade, faz recomendações sobre mudanças quanto ao papel da área. (Wehling et al., 2009). Não há uma definição única a respeito de qual seria esse novo papel, no entanto os autores convergem ao considerar a área um importante agente diante de transformações organizacionais que a estratégia de sustentabilidade demanda.

Sroufe, Liebowitz e Sivasubramaniam (2010) explicitam claramente esta visão ao defender que, além de manter a função de agente de mudança, a gestão de pessoas deve atuar como uma parceira estratégico na disseminação da sustentabilidade. Já para Colbert e Kurucz (2007) a contribuição da área se daria em duas dimensões: uma de intenção e outra de alinhamento. Por um lado, a área deve incentivar a discussão a respeito do tema e uniformizar o entendimento sobre a intenção da empresa quanto à sustentabilidade. Por outro, buscaria um alinhamento de suas ações para auxiliar na realização do intento da sustentabilidade.

Coerentes com esses papéis, a disseminação dos valores e comportamentos relacionados à sustentabilidade também é um tema tratado pelos autores consultados. Quando a sustentabilidade é vista pela empresa como um valor organizacional, torna-se necessário fomentar essa cultura, o que somente pode ser feito quando o RH estimula o compartilhamento do tema no cotidiano de trabalho pelos membros da organização.

Reiterando a centralidade da cultura, Twomey, Twomey e Farias (2010) afirmam que a mudança de foco e objetivos para uma estratégia sustentável pressupõe um processo comportamental que não é simples e localizado. A adesão a esta estratégia implica decisões diárias da empresa, e de cada empregado, que somente ocorrem quando amparadas por valores coerentes com a diretriz traçada pela organização.

Observa-se assim que um dos papéis relevantes de gestão de pessoas identificado pelos autores que relacionam sustentabilidade com RH é o de disseminador estratégico das diretrizes e dos valores organizacionais associados a esse conceito. Tal constatação encontra resguardo na literatura sobre gestão estratégica de RH e, em particular, nas propostas de Ulrich, que defende um modelo organizacional e um profissional de RH que se posicionam como gestores da mudança e parceiros estratégicos. 


\subsubsection{A integração da sustentabilidade na estratégia, nas políticas e práticas da gestão de pessoas}

A integração da sustentabilidade no núcleo das estratégias de Recursos Humanos é um assunto polêmico e contraditório. Rimanoczy e Pearson (2010), por exemplo, afirmam que um novo paradigma estratégico da área de gestão de pessoas busca coerência entre a diretriz de sustentabilidade e as decisões diárias de cada um de seus empregados. Já Boudreau e Ramstad (2005), por seu lado, alegam que a sustentabilidade ainda é pouco constatada nas estratégias de RH das organizações que os autores pesquisaram. Os dados colhidos no levantamento bibliográfico indicam que as mudanças parecem incidir mais nas políticas e práticas da área do que em sua estratégia.

Mesmo no que se refere às políticas e práticas de RH, os pesquisadores demonstram que as mudanças não são completamente abrangentes. Harmon, Fairfield e Wirtenberg (2010) consideram que ações relacionadas com a saúde, segurança, voluntariado, economia e eficiência de energia são mais comuns, enquanto os processos de recrutamento, seleção e recompensa são os últimos a serem adaptados. Além destas práticas, o treinamento, desenvolvimento e a avaliação de resultados configuram-se como processos de $\mathrm{RH}$ que mais sofrem adaptações e que interferem diretamente no comportamento dos empregados segundo Twomey et al. (2010).

De acordo com survey realizada por Sroufe et al. (2010) em empresas norte-americanas, as práticas da área de gestão de pessoas têm sido reconhecidas como importantes nos esforços para a sustentabilidade. Segundo os autores, nas empresas consideradas líderes em sustentabilidade, práticas, tais como recrutamento, desenvolvimento e orientação aos novos empregados são as que sofreram mudanças mais intensas.

Observa-se assim que as pesquisas indicam que as práticas e os processos de $\mathrm{RH}$ são mais suscetíveis às mudanças do que a estratégia da área. Entre elas é mais comum que ocorram alterações nos processos seletivos, de treinamento, integração, orientação e avaliação.

\subsubsection{O papel dos líderes rumo à sustentabilidade}

Para Harmon et al. (2010), a sustentabilidade oferece uma oportunidade para os líderes desempenharem um papel estratégico na gestão das organizações. A discussão sobre liderança e sustentabilidade envolve tanto os líderes da área de gestão de pessoas quanto das demais lideranças da organização.

Segundo a pesquisa realizada por Harmon et al. (2010), os líderes de gestão de pessoas veem a si mesmos e seus pares como pouco competentes, com pouco conhecimento e influência para implementar estratégia para a sustentabilidade, o que inclui a capacidade de traduzir as estratégias da empresa nas atividades de áreas. Para Wirtenberg, Harmon, Russell, e Fairfield (2007) e Rimanoczy e Pearson (2010), esses profissionais pouco compreendem a discussão sobre a sustentabilidade. Por outro lado, é possível encontrar na literatura autores que defendem o papel de agente de mudança das lideranças como inerente à sua função, por este motivo, já habituados aos esforços de mudança, os profissionais estariam aptos a contribuir para a disseminação da estratégia de sustentabilidade (Wehling et al., 2009). Tudo isso indica a necessidade da gestão de pessoas atuar no estímulo à formação e à capacitação desse novo perfil de liderança. Os estudos ainda destacam outros grupos de profissionais nas ações voltadas para a sustentabilidade, como os novos empregados e aqueles considerados como talentos pelas organizações (Colbert \& Kurucz, 2007; Wehling et al, 2009; Sroufe et al, 2010; Twomey et al, 2010; Boudreau \& Ramstad, 2005).

\section{MÉTODO DE PESQUISA}

O método qualitativo mostrou-se mais coerente com o objetivo deste estudo por proporcionar um contato direto do investigador com o objeto de pesquisa. Considera-se que sendo o fenômeno aqui estudado recente e pouco estudado ele pode ser mais bem compreendido quando analisado no contexto em que ocorre. Para Denzin e Lincoln (1994), a pesquisa qualitativa estuda o 
fato em seu ambiente natural, tentando dar sentido ou interpretá-lo de acordo com seu significado para os próprios sujeitos de pesquisa.

Entre as estratégias de pesquisa da abordagem qualitativa, o estudo de caso, segundo Godoy (2006), deve centrar-se em uma situação particular cuja importância vem do que ela revela sobre o fenômeno investigado. Além disso, o aprendizado nos estudos de caso marca a escolha da estratégia de pesquisa. Para Stake (2005), atributos de equilíbrio e variedade são importantes, mas não mais do que a oportunidade de aprender a partir dos casos.

A escolha do caso foi intencional (Gil, 1999) uma vez que se queria buscar empresas típicas, nas quais o fenômeno estudado tivesse maior oportunidade de ocorrer. Por este motivo optou-se por estudar a Natura. $\mathrm{O}$ fator decisivo para esta escolha foi o fato de a organização ter sido considerada empresa-modelo no Guia Exame de Sustentabilidade por 10 anos consecutivos (Editora Abril, 2010). Este anuário, produzido pela mídia especializada, elege empresas como referência em práticas de sustentabilidade no Brasil. Esta escolha apoia-se no pressuposto de que as empresas incluídas na publicação, depois de submetidas aos critérios estabelecidos, são consideradas referências importantes no meio empresarial.

A coleta de dados na empresa ocorreu entre os meses de maio e setembro de 2011 e incluiu o contato inicial, agendamento, as entrevistas (gravadas em áudio digital e transcritas) e a complementação de informações por e-mail. A organização adota um processo formal para atendimento de pesquisadores, por isso esta pesquisa de campo teve apoio do profissional responsável por esta área. As entrevistas ocorreram na sede da empresa, em Cajamar, região metropolitana de São Paulo.

Para a construção deste caso foram entrevistados seis profissionais, entre gerentes, coordenadores e analistas que representaram a gestão de pessoas. O cargo de diretor de sustentabilidade estava vago na época do trabalho de campo desta pesquisa, por este motivo a responsável pela intermediação direcionou o contato para um profissional da área de cultura. Como essa área não está subordinada à Vice-Presidência de RH na Natura, considerou-se que ela poderia contribuir com uma visão externa sobre as relações entre RH e a sustentabilidade.

Como se pode observar na figura 1, para a coleta de dados, adotaram-se três fontes de evidência: documentos, entrevistas baseadas em roteiro e observação direta. A figura 1 apresenta as fontes de pesquisa utilizadas para compor o caso, identificando o entrevistado, as áreas que representam e os códigos utilizados para identificá-los.

\begin{tabular}{|c|c|}
\hline $\begin{array}{l}\text { Entrevistas, } \\
\text { contatos, } \\
\text { códigos e } \\
\text { observações: }\end{array}$ & $\begin{array}{ll}\text { 1) NAT } 1 \text { RH: Presencial (Informante-chave) } & \text { 4) NAT } 4 \text { Cultura: Telefone } \\
\text { 2) NAT } 2 \text { RH: Telefone } & \text { 5) NAT } 5 \text { RH: Telefone } \\
\text { 3) NAT } 3 \text { RH: Presencial } & \text { 6) NAT } 6 \text { RH: Telefone } \\
\text { ** Participação do Painel de Diálogo com Stakeholders sobre a Cultura da Natura - Presencial } \\
\text { ** Visita à fábrica e demais instalações do Espaço Cajamar. }\end{array}$ \\
\hline $\begin{array}{l}\text { Documentos } \\
\text { analisados: }\end{array}$ & $\begin{array}{l}\text { Documentos públicos: } \\
\text { - Website da empresa } \\
\text { - Relatório Natura } 2010 \text { (disponível no site da empresa) } \\
\text { - Projeto Cultura (disponível no Natura Conecta) } \\
\text { - TCC -Desenvolvimento da Liderança (Feliciano, 2010) } \\
\text { Documentos internos: } \\
\text { - Sistema de Gestão Natura (documento impresso) } \\
\text { - Inventário de Reflexão (e-mail) } \\
\text { - Guia do Processo de Gerenciamento de Desempenho (e-mail) } \\
\text { - Revisão dos Comportamentos do PGD Natura (e-mail) }\end{array}$ \\
\hline
\end{tabular}

Figura 1. Fontes de pesquisa e de evidências do Caso Natura

Fonte: Elaborado pelos autores

Inicialmente, os tópicos e objetivos do estudo eram apresentados aos entrevistados e, ao longo da interação, o roteiro tornou-se um guia para a conversa sendo orientado pelo pesquisadorentrevistador. Entre os questionamentos do roteiro, estava a compreensão do conceito de 
sustentabilidade pela empresa, envolvimento das diferentes áreas na temática, além de questionamentos referentes ao papel da área de RH e liderança.

A análise de conteúdo foi utilizada para processamento e discussão dos resultados. Laville e Dionne (1999) afirmam não existirem etapas circunscritas do método, mas, sim, um conjunto de vias possíveis para revelação ou reconstrução do sentido de um conteúdo. Neste estudo, seguiu-se a sugestão dos três polos cronológicos de Bardin (1977): 1) pré-análise; 2) exploração do material; 3) tratamento dos resultados, inferência e interpretação, utilizando-se também outras referências para discussão e encaminhamento dessas etapas (Mattos, 2006).

Como já referido, a bibliografia que une a discussão de sustentabilidade à gestão de pessoas demonstra três focos de integração dos temas, a figura 2 apresenta uma sistematização das categorias e autores que suportam a análise de conteúdo deste trabalho.

\begin{tabular}{|c|c|c|}
\hline Categoria & \multicolumn{2}{|c|}{ Autores } \\
\hline $\begin{array}{l}\text { O papel da área de gestão de pessoas } \\
\text { como agente de mudança estratégica e } \\
\text { disseminadora de valores voltados para a } \\
\text { sustentabilidade }\end{array}$ & $\begin{array}{l}\text { Boudreau e Ramstad (2005) } \\
\text { Colbert e Kurucz (2007) } \\
\text { Freitas, Jabbour e Santos (2009) } \\
\text { Jabbour e Santos (2008) }\end{array}$ & $\begin{array}{l}\text { Sroufe, Liebowitz e } \\
\text { Sivasubramaniam (2010) } \\
\text { Twomey et al (2010) } \\
\text { Wehling et al (2009) }\end{array}$ \\
\hline $\begin{array}{l}\text { A integração da sustentabilidade na } \\
\text { estratégia, nas políticas e práticas da } \\
\text { gestão de pessoas }\end{array}$ & $\begin{array}{l}\text { Bodreau e Ramstad (2005) } \\
\text { Colbert e Kurucz (2007) } \\
\text { Harmon, Fairfield e Wirtenberg } \\
(2010)\end{array}$ & $\begin{array}{l}\text { Rimanoczy e Pearson (2010) } \\
\text { Sroufe, Liebowitz e } \\
\text { Sivasubramaniam (2010) } \\
\text { Twomey et al (2010) }\end{array}$ \\
\hline $\begin{array}{l}\text { O papel dos líderes rumo à } \\
\text { sustentabilidade }\end{array}$ & $\begin{array}{l}\text { Harmon, Fairfield e Wirtenberg } \\
(2010) \\
\text { Jabbour e Santos (2008) } \\
\text { Rimanoczy e Pearson (2010) }\end{array}$ & $\begin{array}{l}\text { Sroufe, Liebowitz e } \\
\text { Sivasubramaniam (2010) } \\
\text { Wehling et al (2009) } \\
\text { Wirtenberg et al (2007) }\end{array}$ \\
\hline
\end{tabular}

Figura 2. Sistematização de autores por categoria

Fonte: Elaborado pelos autores

Por fim, ações, tais como arquivamento dos dados, protocolo do caso, transcrição e aprovação dos respondentes das entrevistas, foram adotadas, como sugerido por Gibbert, Ruigrok e Wicki (2008) para validade interna, externa e confiabilidade da pesquisa.

\section{RESULTADOS DA PESQUISA}

Atuante no setor de produtos de higiene pessoal, perfumaria e cosméticos, a Natura tem crescido de forma veloz. Fundada em São Paulo em 1969, no ano 2000, a empresa tinha cerca de três mil empregados e faturamento próximo a um bilhão de reais; hoje são sete mil empregados e cinco bilhões em vendas. Com um modelo comercial de venda direta, atualmente a organização relaciona-se com 1,2 milhão de consultores que fazem o atendimento, a venda e a entrega dos produtos de forma direta aos consumidores.

Desde 2004, a Natura mantém seu capital aberto na Bolsa de Valores de São Paulo e, nos últimos cinco anos consecutivos, no Índice de Sustentabilidade Bovespa - ISE. A figura 3 apresenta uma síntese da caracterização geral do caso, com informações identificadas pelas entrevistas e pela análise documental.

\begin{tabular}{|l|l|}
\hline Histórico de envolvimento no tema da sustentabilidade & Fundadores e posicionamento de mercado. \\
\hline $\begin{array}{l}\text { Análise da sustentabilidade nas declarações de missão, visão } \\
\text { e valores }\end{array}$ & $\begin{array}{l}\text { Menciona-se: desenvolvimento sustentável, } \\
\text { construção de um mundo melhor e diversidade. }\end{array}$ \\
\hline Sustentabilidade na estratégia de atuação & Direcionadores de Cultura e Sistema de Gestão. \\
\hline Formas de Institucionalização & Diretoria de Sustentabilidade. \\
\hline
\end{tabular}

Figura 3. Caracterização geral do caso Natura

Fonte: Elaborado pelos autores

Segundo declarações de missão, visão e valores, a Natura revela seu comprometimento com a construção de um mundo melhor, a busca pelo estar bem e o bem-estar nas relações por meio de 
seus produtos, o desejo de uma expressão mundial da marca, a interdependência pelo dinamismo das relações entre a empresa, as pessoas e a natureza. A organização faz menção direta ao desenvolvimento sustentável, e com uma análise mais detida, é possível identificar que as diretrizes transmitem uma preocupação com a longevidade da sociedade. A gestão baseada em valores, pretendida pelos fundadores, ao que parece, torna a Natura uma empresa constantemente preocupada com sua essência.

Para tornar a linguagem dessa essência mais objetiva e tangível, a empresa formalizou uma Diretoria de Sustentabilidade, um Sistema de Gestão e os "direcionadores de cultura". Os direcionadores reforçam sua estratégia tornando-a mais tangível e objetiva, conforme afirma um de seus interlocutores (NAT 4 Cultura), sendo que um deles menciona diretamente a sustentabilidade, estimulando uma entrega de valor nas dimensões econômica, social e ambiental e o compromisso da gestão de curto prazo atrelada ao futuro da empresa.

Seu Sistema de Gestão vem sendo concebido desde 2008. Como se observa na Figura 4, nele é possível evidenciar elementos, tais como sociedade, marca, cultura, liderança, indivíduos, estratégias e planos, processos, relação com stakeholders, produtos e serviços, canais, comportamento empresarial, clientes, aprendizagem, inovação, além de resultados coerentes ao triple bottom line.

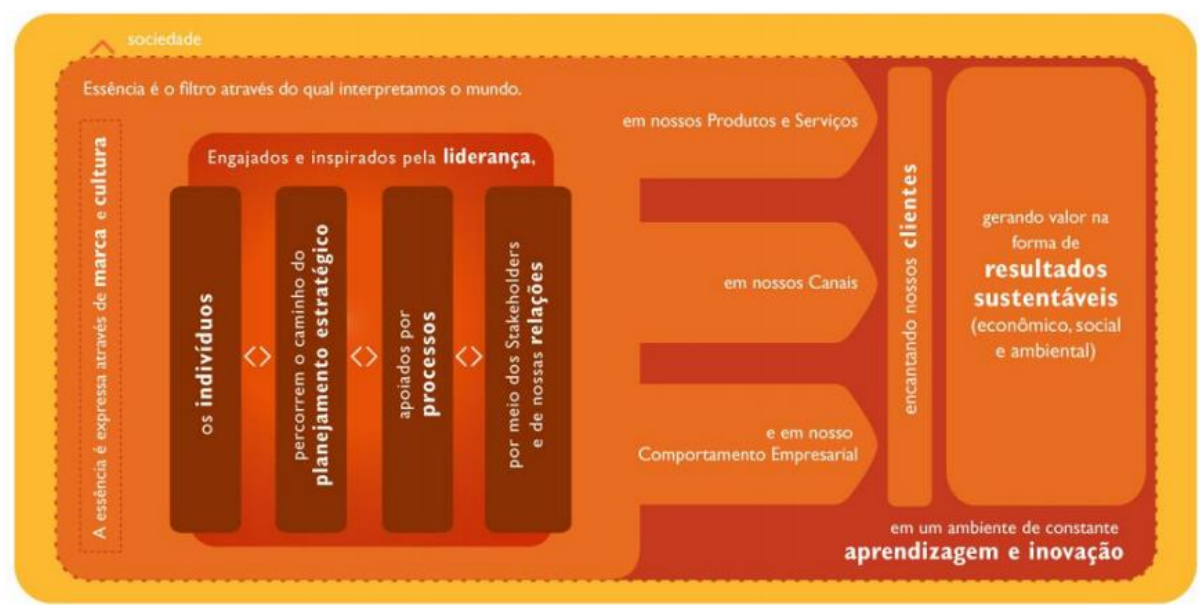

Figura 4. Sistema de Gestão Natura

Fonte: Sistema de Gestão Natura, 2011, p. 1. (Documento interno)

Durante a entrevista, o interlocutor NAT 1 RH demonstrou como deve ser feita a leitura do Sistema de Gestão Natura a partir da Figura 4. O início da leitura dessa imagem começa com a observação de que a Natura está inserida em uma sociedade, o que, de acordo com a empresa, já representa a ideia de interdependência. É a partir dos indivíduos que o Sistema demonstra a sustentação do Planejamento Estratégico - PE - da Natura. No fim, para a Natura, este Sistema objetiva geração de valor sob a perspectiva do triplo resultado - econômico, social e ambiental - em um ambiente de constante aprendizado e inovação. A sustentabilidade surge como o objetivo final da gestão da empresa e, por isso, pode ser considerada de forma transversal em todo o Sistema.

Quando a gente olha no mercado, aonde a gente olha para os indivíduos como centro da empresa, né? [...] Elas (as empresas) não olham para o indivíduo. Então o que a gente fala aqui, tudo começa com o indivíduo com a sua motivação, seus valores, seus interesses [...] (NAT 1 RH, L: 169-174).

Segundo o interlocutor, o conceito da sustentabilidade está permeado em toda a sua cadeia de produção e todas as suas relações, desde quando se faz o contato com os extrativistas, a forma como a empresa se relaciona com eles, como é organizado o processo de venda, até o envolvimento dos consultores Natura e o relacionamento com os consumidores. 
Já a Diretoria de Sustentabilidade mantém este olhar transversal sobre os processos, questiona as áreas sobre o alinhamento destes com o planejamento estratégico, mobiliza o tema, dissemina práticas e orienta sobre o conceito e o direcionamento mais adequado.

[...] a Diretoria de Sustentabilidade hoje, ela é o que eu chamo de bate-bumbo, ela dá o ritmo. Ela diz é mais para cá, é menos para cá. Por quê? Por que às vezes, se você não tem um olhar transversal, mas que seja o dono desse processo, né? (NAT 1 RH, L, p. 58-62).

Então não tem uma atuação de uma área fazendo o processo rodar e o resto ajuda ou não ajuda. Não tem escolha. A gente tem que fazer efetivamente sustentabilidade rodar. (NAT 1 RH, L, p. 7-9).

Vale destacar o papel de ritmo, de "bater o bumbo" dado à Diretoria de Sustentabilidade, que, dessa forma, atua em conjunto com diferentes áreas, entre elas gestão de pessoas. Os processos de gestão de pessoas têm sido orientados pelo conceito de sustentabilidade e serão conhecidos na próxima seção de descrição deste caso.

\subsection{Gestão de Pessoas na Natura}

De acordo com a interlocutora-chave, uma das mais importantes questões do PE da Natura é ter pessoas cada vez mais alinhadas com a essência da organização. Ao que parece, esse caminho tem sido percorrido pela área de gestão de pessoas, pois a reflexão, os projetos piloto e as mudanças efetivas nesse sentido já começaram.

Ao analisar a própria gestão da Natura, segundo um dos entrevistados (NAT RH 1), observou-se que os processos dentro da área não mais seguiam a vanguarda desejada e não alcançavam os resultados pretendidos.

O que que a gente pode fazer diferente para a gente ter melhores resultados? E aí, a gente entendeu pela Natura ter essa característica, dessa dependência profunda dela, porque [...] a Natura é muito particular, ela é muito dependente da essência dela, então se você não se adequa a esses valores, a essa essência, você patina. Então a gente entendeu que essa era a chave, vamos identificar pessoas, vamos tentar buscar esse alinhamento, né? (NAT 3 RH, L. p. 299-306).

Com isso, os profissionais da área, com apoio da alta liderança, iniciaram um questionamento sobre o estado atual das políticas e práticas da empresa e todos os processos e subprocessos começaram a ser revistos no ano de 2009.

Em relação aos profissionais de recursos humanos, vê-se que eles têm uma importante atuação para a sustentabilidade, tornando a área um exemplo e agente motivador para a incorporação do conceito pelas pessoas e demais áreas.

O que a gente fala é que a área de RH, o processo de gestão de pessoas, precisa ser único, a gente precisa puxar a agenda das pessoas. Ou seja, a gente tem que ser um motivador da transformação das demais áreas da empresa. [...] ser protagonista nesse sentido e atuar como modelo. Não adianta a gente puxar e falar, a gente precisa praticar algumas coisas para que a organização entenda que faz sentido. (NAT 3 RH, L.,p. 8-20).

Nesse caso, a área de RH se vê como protagonista, com responsabilidade de trazer o tema à tona na organização, praticá-lo por meio de suas políticas e estimular outras áreas para que sigam seu modelo e atuação. Ao que parece, a área de gestão de pessoas posiciona-se de forma estratégica para a incorporação e vivência da sustentabilidade na Natura.

Outro aspecto a ser discutido refere-se à liderança. Documentos e relatos das entrevistas apontam que o desenvolvimento de uma liderança alinhada com sua essência e estratégia é fundamental para o crescimento da organização. Assim como a proposta de atuação da área de gestão de pessoas, o informante-chave afirma que o papel do líder na Natura é de protagonismo.

Então aqui a liderança é que faz, eu brinco assim: Ela faz essa sopa mexer, ela faz esse caldo, ela tem esse tempero. Eles são responsáveis por fazer isso acontecer. [...] como eu desenvolvo essas pessoas para que

Revista de Gestão Social e Ambiental - RGSA, São Paulo, v. 8, n. 1, p. 54-72, jan./abr., 2014. 
elas sejam exemplos vivos, de novo, marca, cultura, que elas sejam protagonistas e sendo alinhado com a estratégia da empresa, tá. (NAT 1 RH, L.p. 237-241).

Além disso, foram mencionados os papéis desempenhados pela área de gestão de pessoas e da liderança da empresa, ao longo das entrevistas, políticas e práticas de gestão de pessoas, demonstrando uma busca pelo alinhamento com o conceito da sustentabilidade.

\subsection{As políticas e práticas de RH integradas à sustentabilidade}

A partir da coleta de dados foi possível perceber que organização vivencia hoje um processo de revisão de suas políticas e práticas de $\mathrm{RH}$. As práticas nas quais se identificou alguma integração com a questão da sustentabilidade serão relatadas a seguir.

\subsubsection{Atração}

Em 2011, um novo modelo de atração e seleção foi desenvolvido com foco na busca de profissionais alinhados aos propósitos e valores da empresa, além de capacitados tecnicamente. Depois das etapas de análise de currículo e entrevista, o candidato é convidado a preencher um instrumento denominado como Inventário de Reflexão. Segundo o interlocutor NAT 3 RH, este é um instrumento que permite um processo de autoconhecimento do candidato e possibilita que a empresa conheça qual sua história de vida e seus propósitos e de que maneira estão alinhados aos da organização.

O inventário, além dos valores, busca coletar informações mais práticas que estão entre os desejos e as intenções dos candidatos e verifica o alinhamento também, de forma mais prática, ao dia a dia de trabalho, as práticas de remuneração e os estilos de gestão encontrados nas áreas e organização. A equipe de atração e os RHs de área foram capacitados, no entanto os gestores, que lidam com esse instrumento, ainda não foram envolvidos nesses treinamentos.

\subsubsection{Integração de novos empregados}

Quando contratados, todos os novos empregados da organização passam por um processo de integração, sendo a primeira semana considerada como a "integração à essência". Os participantes recebem informações relacionadas aos temas estratégicos da organização, sendo a sustentabilidade um deles. Segundo o interlocutor NAT $1 \mathrm{RH}$, esse tema permeia todas as apresentações direcionadas a esse público, por ser esta uma bandeira forte da Natura. Há, também, abordagens mais diretas com apresentações exclusivas sobre os conceitos de sustentabilidade e diversidade. Já para os profissionais que assumirão papéis de gestão na organização, há workshops dos temas estratégicos (sustentabilidade, marca, relacionamento, por exemplo) para aprofundamento dos conceitos.

\subsubsection{Engajamento}

A intenção do engajamento é fazer com o que o empregado se mantenha conectado à Natura. De acordo com os interlocutores, "reter" representa uma ação autoritária e não oferece escolha à pessoa de ser protagonista de sua história, por isso a empresa afirma não adotar um processo de retenção, mas de engajamento. Esta política envolve encontro com grupos de empregados, o primeiro momento objetivando a reflexão do próprio empregado; em um segundo, a apresentação dos propósitos da Natura e, por fim, a busca pela intersecção e identificação entre empresa e empregado. Os encontros têm envolvido todos os empregados, e se iniciaram em março de 2010 e, no momento da pesquisa, encontravam-se em andamento.

\subsubsection{Aproveitamento interno}

Revista de Gestão Social e Ambiental - RGSA, São Paulo, v. 8, n. 1, p. 54-72, jan./abr., 2014. 
A política de aproveitamento interno pretende priorizar a promoção dos empregados da Natura antes de buscar profissionais no mercado. Para isso, há uma política de aproveitamento interno estabelecida e um arcabouço para monitoramento e garantia de que este seja um princípio das promoções e contratações da empresa.

[...] a gente entende que uma vez que o alinhamento de propósitos e valores é tão importante e a Natura é uma empresa tão dependente dessa cultura, que mesmo que você tenha um gap em termos técnicos, o que você traz já com um colaborador com alinhamento dessa cultura, ela vai suprir o gap que você tem em relação a uma pessoa que está no mercado. (NAT 3 RH, L.p. 55-60).

A organização estabeleceu também um Comitê de Atração que acompanha todos os processos que demandam contratação externa. Equipe de atração, diretoria e gerente da área contratante, entre outros, buscam pelo profissional dentro da própria organização. Apenas nos casos em que as alternativas estejam esgotadas, o processo é aberto para o mercado. O entrevistado (NAT $3 \mathrm{RH}$ ) ressalta que existem desafios inerentes a essa mudança como os efeitos colaterais pelo fechamento prematuro de ciclo de desenvolvimento em determinadas promoções e também o comprometimento dos gestores da organização com a política.

\subsubsection{Treinamento e desenvolvimento}

Os temas de treinamento abarcam os técnicos e também abordagens pautadas na essência da Natura. Segundo os entrevistados, há treinamentos que tratam diretamente de sustentabilidade, enquanto outros trazem de forma tangencial o que esse conceito representa e como deve ser vivenciado no dia a dia de trabalho.

\subsubsection{Gestão de desempenho}

O Processo de Gerenciamento de Desempenho - PGD - visa acompanhar o desenvolvimento e mapeamento do desempenho dos empregados, e é composto por cinco etapas: contratação de performance, avaliação de aderência à essência, reunião de consistência, ciclo de feedback e plano de desenvolvimento individual - PDI. Com um olhar mais atento à avaliação de desempenho - segunda etapa do PGD - vê-se que esta avaliação foi revisada para que representasse uma das políticas de RH a apoiar a estratégia da Natura.

Muitas empresas fazem avaliação por competências. A Natura faz a avaliação pelos comportamentos que acredita e valoriza. É nesse momento que se avalia a sustentabilidade. (NAT 2 RH, L.p. 35-37).

Foi possível perceber que a avaliação de desempenho dos empregados é composta por dois eixos x e y, representados pela Figura 55.
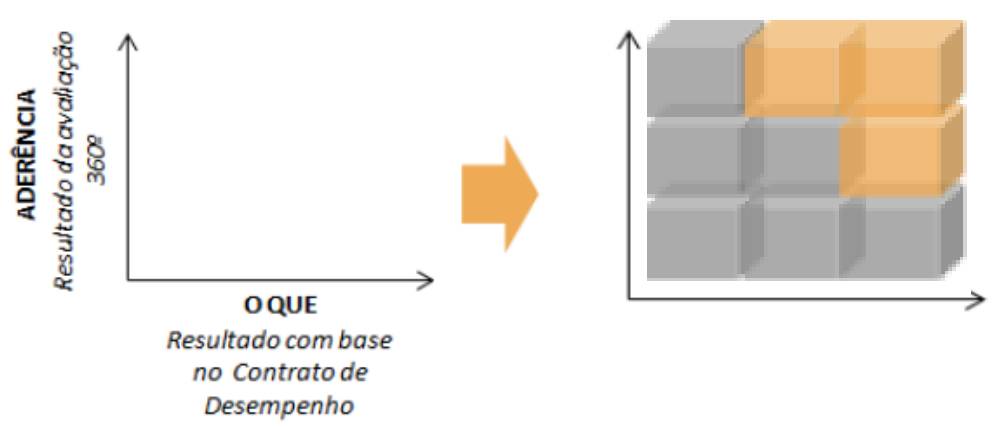

Figura 5. Matriz de Avaliação de Desempenho

Fonte: Adaptado de Feliciano, 2010, p. 30. 
Os eixos representam (a) O que o empregado entrega (resultado do contrato de performance entre empregado e gestor) e (b) Como o empregado entrega (avaliação de aderência à essência), o último relacionado aos comportamentos esperados.

A Natura mantém um guia com a descrição desses comportamentos em quatro dimensões: autoconhecimento, protagonismo, relacionamento e sustentabilidade. Nesse documento é possível identificar comportamentos esperados de todos os empregados e aqueles que se referem exclusivamente aos gestores. Todas as dimensões de avaliação oferecem aos empregados exemplos de três comportamentos que variam do não atendimento ao comportamento desejado. A figura 6 apresenta um dos comportamentos descritos da dimensão sustentabilidade.

\begin{tabular}{|c|c|c|c|}
\hline \multicolumn{3}{|c|}{ Comportamentos da Dimensão Sustentabilidade } & Público \\
\hline 1 & 2 & 3 & \multirow[b]{2}{*}{$\frac{n}{0}$} \\
\hline $\begin{array}{l}\text { Faz o seu trabalho } \\
\text { sem levar em } \\
\text { consideração os } \\
\text { desafios } \\
\text { socioambientais. }\end{array}$ & $\begin{array}{l}\text { Identifica e incorpora os desafios } \\
\text { socioambientais no seu trabalho com } \\
\text { o objetivo de gerar resultados } \\
\text { econômicos, ambientais e sociais de } \\
\text { forma integrada. }\end{array}$ & $\begin{array}{l}\text { Destaca-se por estimular os outros na } \\
\text { identificação e incorporação dos desafios } \\
\text { socioambientais ao objetivo de gerar } \\
\text { resultados econômicos, ambientais e sociais } \\
\text { de forma integrada. }\end{array}$ & \\
\hline
\end{tabular}

Figura 6. Comportamentos da Dimensão Sustentabilidade

Fonte: Revisão dos Comportamentos do PGD Natura, 2011, p. 18-20 (Documento Interno).

Nesse exemplo, vê-se um comportamento esperado relacionado ao triplo resultado. Ainda dentro do Processo de Gerenciamento de Desempenho, foi possível perceber a adoção recente da avaliação $360^{\circ}$ que, segundo o informante-chave, mostra o alinhamento dos sistemas de recursos humanos à sustentabilidade. Esta avaliação foi revista em 2011, com uma ação piloto abrangendo públicos externos à organização.

A gente criou esse ano uma avaliação $360^{\circ}$, incluindo familiares e suas relações externas à Natura. Algumas pessoas, como eu, eu fui avaliada pelo meu marido, pelos meus fornecedores, fui avaliada pelas pessoas que eu me relaciono fora, por amigos, enfim. A gente começa a ampliar um pouco sobre os valores, sobre a aderência à essência e como eu estou lá fora. Princípio dessa história tá no princípio de que a gente... quando a gente fala que quer gente engajada e inspirada, não só trabalhando. Mas que ela seja exemplo dessa essência, então é importante você começar a medir, entender como é a evolução disso. (NAT 1 RH, L. p. 495-502).

Essa iniciativa envolveu os stakeholders na avaliação dos empregados e apresenta-se como uma prática coerente ao conceito da sustentabilidade. A iniciativa piloto de avaliação com inclusão das relações externas foi feita voluntariamente por um pequeno grupo de empregados. A extensão dessa prática para toda a organização encontrava-se sob análise da área jurídica. Para o informantechave, algumas mudanças pretendidas pela área de RH esbarram em questões legais, como o caso dessa avaliação.

\subsubsection{Remuneração}

Em relação à remuneração, destaca-se o atrelamento da remuneração variável às metas financeiras, sociais e ambientais, oriundas do PE e da Matriz de Materialidade ${ }^{i}$.

A gente escolhe temas que a gente quer dar foco e coloca no individual e no todo a gente sempre traz alinhamento com a estratégia que a empresa está fazendo. (NAT 1 RH - Natura, L.p. 580-582).

Desde 2009, a PLR envolve cinco variáveis relacionadas aos aspectos econômicos, sociais e ambientais e seus respectivos pesos na meta total: a) Resultado financeiro dado pelo EBTIDA ${ }^{\text {ii }}$ $(80 \%)$; b) Clima organizacional $(5 \%)$; c) Lealdade das consultoras Natura (5\%); d) Índice de não atendimento (5\%) e, por fim; e) Emissão de carbono (5\%). As metas de clima organizacional interno, emissão de carbono e de lealdade das consultoras (este índice envolve aspectos referentes a 
satisfação, intenção de continuar e recomendação sob a percepção das consultoras) são consideradas pela empresa como metas socioambientais.

Dentro da política de remuneração, o entrevistado NAT 5 RH considera a participação nos lucros e os resultados gerencial - PLR - um ponto forte para mobilização da liderança. A PLR do grupo gerencial aparece como um gatilho do triplo resultado e os demais empregados estão envolvidos nessa perspectiva dos 3Ps a partir do desmembramento das metas. Contudo, as metas socioambientais não estarão necessariamente nas contratações de performance, o que depende da negociação realizada entre empregado e gestor direto.

Desde 2005, indicadores socioambientais estão relacionados ao PLR dos gestores. Nos anos de 2005, 2006 e 2007, as variáveis eram venda de refil e impacto ambiental. As variáveis denominadas sociais estão pautadas no tema das "relações" que a organização prioriza e a ambiental é oriunda da Matriz de Materialidade. Em 2008, os indicadores estavam pautados na redução de emissão de carbono e do consumo de água. Segundo o interlocutor NAT 5 RH, o cálculo de carbono foi uma variável integrada à remuneração variável de todos os empregados da Natura em 2009 e o envolvimento dessas variáveis tridimensionais não apresenta resistência dos empregados.

\subsubsection{Benefícios}

No que tange aos benefícios, ao que parece, a organização procura utilizá-los para mobilizar seus empregados em direção à cultura Natura. Para o entrevistado NAT 6 RH, todas as políticas de benefício têm um viés para a questão da sustentabilidade, pois a premissa de elaboração e implantação está amparada nos resultados de longo prazo. A intenção é oferecer e pensar sustentabilidade por meio dos benefícios.

As metodologias na Natura sempre têm o olhar para o triple bottom line. (NAT 6 RH, L: 22).

Entre os benefícios ofertados pela empresa, destaca-se o cartão combustível oferecido aos executivos e à força de vendas. Em uma atuação piloto, desde o início de 2011, os empregados da força de vendas recebem um cartão combustível para reembolso exclusivo de etanol. Sendo um combustível de fonte de energia renovável e, mesmo com preço comercializado acima dos demais, cerca de 800 veículos têm sido envolvidos nessa política piloto. A implantação desse tipo de benefício é reconhecida como um grande desafio. Segundo o entrevistado, o desafio, no primeiro momento, é a aprovação do benefício. Os custos dessas propostas mostram-se altos quando comparados às iniciativas sem diferenciação, por isso devem estar amparadas por vários estudos de viabilidade. No entanto, segundo o interlocutor, por ser a Natura uma organização que preza pela sustentabilidade, estas são iniciativas que se tornam possíveis.

\subsubsection{Sucessão}

A organização iniciou em 2010 o mapeamento das posições críticas de sucessão e, em 2011, o levantamento de todas as posições de gestão com a identificação de quem serão os gestores de curto, médio e longo prazo. Esse grupo de sucessores tem origem na Matriz de Avaliação de Desempenho, pela qual os empregados são avaliados por seus resultados e também pela aderência à essência, conforme apresentado na Figura 55. Percebe-se que os profissionais que ocuparão futuras posições de liderança na Natura são valorizados tanto pelo alcance de resultados quanto por seu alinhamento à cultura da organização, o que reforça o objetivo organizacional de ter gestores que sejam exemplos vivos de sua essência. Os empregados que compõem o grupo de sucessão são os que alcançam resultados na área superior direita da matriz, o que é denominado "L invertido" (em destaque na Figura 5).

Outra política encontrada é que a pretensão da empresa no que se refere à sucessão deve estar de acordo com o que o empregado pretende em sua vida profissional e pessoal (aspectos relatados em seu PDI). Nesse sentido, o entrevistado NAT RH 1 afirma que sua política está de 
acordo com seu Sistema de Gestão que se inicia no indivíduo. Para exemplificar essa diretriz, destaca-se um caso na Natura que explicita a importância dessa ação, em que o objetivo da organização não estava alinhado ao objetivo do profissional.

Tem uma diretora que é super bem-conceituada e todo mundo gostaria dela e de tê-la em qualquer lugar. E ela estava sempre sendo chamada no pipeline para a América Latina. E ela escreve claramente no seu PDI dizendo assim: 'Eu não tenho mobilidade para a América Latina'. Então, a gente derrubou um processo de anos achando que tinha um sucessor e não tinha, não é? (NAT 1 RH, L.p. 407-412).

Assim, além de manter pessoas alinhadas com a essência da Natura, pretendem-se resultados mais efetivos de suas políticas.

\section{ANÁLISE E DISCUSSÃO DOS RESULTADOS}

Pode-se observar que a sustentabilidade está presente nas declarações de missão, visão, valores da empresa e também do sistema de gestão, sendo que a análise desta última fonte permite afirmar que o conceito está amparado nos três pilares - econômico, social e ambiental - de Elkington (2001). As entrevistas e os documentos permitem afirmar que a interpretação do conceito mostra-se ligada à forma como seus fundadores compreendem a sustentabilidade e como a empresa se esforça para que se perpetue como um valor organizacional, tópico presente no discurso dos entrevistados. Esse esforço de alinhamento da cultura, presente nos programas de integração de novos empregados, por exemplo, gera, inclusive, uma expectativa aos profissionais ingressantes de que a empresa não opera no mesmo ritmo de busca por resultados como as demais empresas do mercado, no entanto não é isso que demonstra no dia a dia de trabalho, que se mostra acelerado e em busca de resultados financeiros como qualquer outra organização.

No que tange ao papel da área de gestão de pessoas, os resultados apontam para a intenção da área se assumir como protagonista, posicionando-se de forma estratégica e buscando atuar como gestora da mudança. Estes resultados coincidem com os papéis estratégicos propostos por Ulrich (2000) e por autores da literatura conjunta, como Wehling et al. (2009), Sroufe et al. (2010) e Colbert e Kurucz (2007).

Os profissionais entrevistados de RH e de outras áreas da empresa também consideram que é essencial que as lideranças assumam a estratégia de sustentabilidade. Assim, o caso da Natura ratifica também a importância do líder protagonista, defendida pelos estudos de Harmon et al (2010). No dia a dia da empresa, observou-se que há um discurso declarado e um esforço dos profissionais de RH em assumir esse protagonismo da liderança, contudo, não há uma coerência entre todos os líderes, visto que alguns ainda não internalizaram as políticas de RH que sustentam o conceito de sustentabilidade como, por exemplo, o aproveitamento interno.

Mudanças importantes foram detectadas nos procedimentos de seleção, de avaliação de desempenho e de recompensa e nas ferramentas nucleares da gestão de pessoas. Quanto a gestão de desempenho e remuneração, destaca-se que as metas socioambientais não estarão necessariamente nas contratações de performance dos empregados, o que depende da negociação realizada entre empregado e gestor direto. Além disso, considerando a sustentabilidade um conceito transversal, discute-se a explicitação do conceito em uma dimensão específica do comportamento "compromisso com a sustentabilidade" - e a não adoção do conceito de forma transversal nos demais comportamentos avaliados. Vale destacar que as políticas de benefícios e sucessão, que não haviam sido citadas pela literatura até aqui, também sofreram alterações por conta da opção pela sustentabilidade.

\section{CONSIDERAÇÕES FINAIS}

O referencial teórico deste estudo permitiu compreender o movimento do desenvolvimento sustentável no contexto social e seus impactos no âmbito das organizações. A sustentabilidade mostrou-se como um fator contingencial que passa, cada vez mais, a ser percebido e integrado à

Revista de Gestão Social e Ambiental - RGSA, São Paulo, v. 8, n. 1, p. 54-72, jan./abr., 2014. 
estratégia de parte expressiva das empresas destacadas no cenário nacional e internacional. Segundo a literatura consultada, essa conexão tem impactos no sistema de recursos humanos, uma vez que essas transformações organizacionais dependem do comportamento das pessoas e, por decorrência, das políticas e práticas de RH.

Como contribuição para abordagem dessa temática, este estudo propôs-se a verificar se ocorrem mudanças significativas nas políticas e práticas de gestão de pessoas das empresas que incorporam a sustentabilidade em sua estratégia de negócios.

Os resultados desta pesquisa permitem demonstrar que, no caso da Natura, a área de gestão de pessoas foi envolvida na viabilização desta estratégia, o que implicou a revisão das políticas e práticas de $\mathrm{RH}$.

O termo "protagonismo", referido várias vezes nas entrevistas, retrata simbolicamente o papel que se espera, tanto da área de gestão de pessoas, quanto dos líderes de toda a organização. A intenção é de que estes sejam exemplos organizacionais e comportamentais da intenção estratégica que se busca alcançar. Destaca-se o relato de um movimento organizacional para mudanças do sistema de gestão de pessoas e evidencia-se aqui uma intenção deliberada de orientar a atuação humana a partir das mudanças realizadas nas políticas e práticas de $\mathrm{RH}$, estimulada, principalmente, pelo crescimento da organização e a necessidade percebida de reforço e alinhamento dos empregados aos valores.

Seleção, desempenho, remuneração, benefícios e sucessão foram alinhados à sustentabilidade, à medida que as políticas e práticas foram repensadas para refletir tal valor, com mudanças nos processos e instrumentos. Internalização da política de aproveitamento interno, aprovação interna de benefícios, como o combustível de fonte de energia renovável, e metas socioambientais para os empregados surgem como desafios à mudança.

As três categorias identificadas na literatura que integra gestão de pessoas e sustentabilidade - o papel da área de RH, a adaptação das políticas e práticas de RH e o papel dos líderes - puderam ser constatadas a partir da pesquisa empírica.

Como limitação do trabalho, admite-se que os resultados obtidos dependeram, em grande parte, do discurso formalmente redigido ou verbalizado pelos representantes da organização. Em segundo lugar, ressalta-se que os limites do método de investigação do estudo de caso permitem que se relacionem as descobertas apenas à empresa estudada. Entende-se, porém, que estes resultados são suficientemente convincentes para instigar futuras pesquisas com o desafio de investigar se esta retórica vem se tornando realidade. Para tanto, considera-se essencial abordar essa questão da ótica dos empregados, o que, de fato, orienta seus comportamentos nas organizações que caminham rumo à sustentabilidade.

\section{REFERÊNCIAS}

Abramovay, R. (2010) O discurso ambientalista continuará precário enquanto não desenvolver uma compreensão mais refinada sobre o que é o mercado. In: Arnt, R. O que os economistas pensam sobre a sustentabilidade. São Paulo, 34, 265-281.

Barbieri, J. C., Vasconcelos, I. F. G., Andreassi, T. \& Vasconcelos, F. C. (2010) Inovação e sustentabilidade: novos modelos e proposições. Revista de Administração de Empresas, 50(2), 146154.

Bardin, L. (1977) A análise de conteúdo. Lisboa: Edições 70.

Boudreau, J. W. \& Ramstad, P. (2005) M. Talentship, talent segmentation, and sustainability: a new HR decision science paradigm for a new strategy definition. Human Resource Management, 44(2), 129-136. 
Boxall, P. \& Purcell, J. (2008) Strategy and human resource management: management, work and organisations. (2a ed.). New York: Palgrave Macmillan.

Claro, P. B. O., Claro, D. P. \& Amâncio, R. (2008) Entendendo o conceito de sustentabilidade nas organizações. Revista da Administração da Universidade de São Paulo, 43(4), 289-300.

Colbert, B. A. \& Kurucz, E. C. (2007) Three conceptions of triple bottom line business sustainability and the role for HRM. Human Resource Planning, 30(1), 21-29.

Comissão Mundial Sobre Meio Ambiente e Desenvolvimento - CMMAD. (1991) Nosso futuro comum. ( $2^{\mathrm{a}}$ ed.). Rio de Janeiro: Fundação Getulio Vargas.

Denzin, N. K. \& Lincoln, Y. S. (1994) Introduction: entering the field of qualitative research. In: Denzin, N. K. \& Lincoln, Y. S. (Org.). Handbook of qualitative research (1-17). Thousand Oaks: Sage.

Doppelt, B. (2010) Leading change toward sustainability: a change management guide for business, government and civil society. ( $2^{\mathrm{a}}$ ed.). Sheffield, UK: Greenleaf.

Editora Abril. (2010) Guia Exame de Sustentabilidade. São Paulo: Abril.

Elkington, J. (2001) Canibais com garfo e faca. São Paulo: Makron Books.

Esteves, S. A. P. (2009) Verdades portáteis: dilemas, desafios conceituais e limites da sustentabilidade no plano organizacional (Tese de Doutorado em Administração). Fundação Getulio Vargas, São Paulo, SP, Brasil.

Faber, N., Jorna, R. \& Engelen, J. V. (2005) The sustainability of "sustainability": a study into the conceptual foundations of the notion of "sustainability". Journal of Environmental Assessment Policy and Management, 7(1), 1-33.

Feliciano, P. A. (2010) Desenvolvimento da liderança: desafios atuais e futuros: estudo de caso da Natura (Monografia de MBA Executivo Internacional). Fundação Instituto de Administração, São Paulo, SP, Brasil.

Fleury, M. T. L.\& Fischer, R. M. (1998) Gestão de pessoas: os desafios de aproximar a teoria da prática e vice-versa. Revista de Administração da Universidade de São Paulo, 33(2), 90-94.

Gibbert, M., Ruigrok, W. \& Wicki, B. (2008) Research notes and commentaries: what passes as a rigorous case study? Strategic Management Journal, 29, 1465-1474.

Gil, A. C. (1999) Métodos e técnicas de pesquisa social. São Paulo: Atlas.

Gladwin, T. N., Kennelly, J. J., Krause, T. S. (1995) Shifting paradigms for sustainable development: implications for management theory and research. Academy of Management Review, 20 (4), 874-907.

Godoy, A. S. (2006) Estudo de caso qualitativo. In Godoi, C. K. et al. (Org.). Pesquisa qualitativa em estudos organizacionais: paradigmas, estratégias e métodos (115-146). São Paulo: Saraiva. 
Harmon, J., Fairfield, K. D. \& Wirtenberg, J. (2010) Missing an opportunity: HR leadership and sustainability. People and Strategy, 33(1), 16-21.

Hart, S. L. (2006) O capitalismo na encruzilhada: as inúmeras oportunidades de negócios na solução dos problemas mais difíceis do mundo. Porto Alegre: Bookman.

Lacombe, B. M. B. \& Chu, R. A. (2008) Políticas e práticas de gestão de pessoas: as abordagens estratégica e institucional. Revista de Administração de Empresas, 48(1), 25-35.

Laville, C. \& Dionne, J. (1999) A construção do saber: manual de metodologia da pesquisa em ciências humanas. Belo Horizonte: UFMG.

Legge, K. (2005) Human resources, realities and rethorics. London: Palgrave.

Lengnick-Hall, M. L., Lengnick-Hall, C. A., Andrade, L. S. \& Drake, B. (2009) Strategic human resource management: the evolution of the field. Human Resource Management Review, 19(2), 6485.

Lepak, D. P. \& Shaw, J. D. (2008) Strategic HRM in North America: looking to the future. The International Journal of Human Resource Management, 19(8), 1486-1499.

Martín-Alcázar, F. Romero-Fernández, P, M. \& Sánchez-Gardey, G. (2005) Strategic human resource management: integrating the universalistic, contingent, configurational and contextual perspective. The International Journal of Human Resource Management, 16(5), 633-659.

Mattos, P. L. C. L. (2006) Análise de entrevistas não estruturadas: da formalização à pragmática da linguagem. (2006). In Godoi, C. K. et al. (Org.) Pesquisa qualitativa em estudos organizacionais: paradigmas, estratégias e métodos. São Paulo: Saraiva, 347-373.

Oliveira, J. A. P. (2008) Empresas na sociedade: sustentabilidade e responsabilidade social. Rio de Janeiro: Elsevier.

Rimanoczy, I. \& Pearson, T. (2010) Role of HR in the new world of sustainability. Industrial and Commercial Training, 42(1), 11-17.

Roehling, M. V. et al. (2005). The future of HR management: research needs and directions. Human Resource Management, 44(2), 207-216.

Savitz, A. W. \& Weber, K. (2007) A empresa sustentável: o verdadeiro sucesso é o lucro com responsabilidade social e ambiental. Tradução Afonso Celso da Cunha Serra. Rio de Janeiro: Elsevier.

Senge, P. M., Smith, B., Kruschwitz, N., Schley, S. \& Laur, J. (2009) A revolução decisiva: como indivíduos e organizações trabalham em parceria para criar um mundo sustentável. Tradução Afonso Celso da Cunha Serra. Rio de Janeiro: Elsevier.

Sroufe, R., Liebowitz, J. \& Sivasubramaniam, N. (2010) Are you a leader or a laggard? HR's role in creating a sustainability culture. People and Strategy, 33(1), 34-42.

Stake, R. E. (2005) The art of case study research. Thousand Oaks: Sage. 
Twomey D. F., Twomey, R. F. \& Farias, G. (2010) Human values and sustainability: can green swim upstream? People and Strategy, 33(1), 52-59.

Ulrich, D. (Org.) (2000) Recursos humanos estratégicos: novas perspectivas para os profissionais de RH. São Paulo: Futura.

Veiga, J. E. (2010). Sustentabilidade: a legitimação de um novo valor. São Paulo: Senac.

Wehling, C. et al. (2009) An exploratory study of the role of HRM and the transfer of German MNC sustainability values to Brazil. European J. International Management, 3(2), 176-198.

Wirtenberg, J., Harmon, J., Russell, W. G. \& Fairfield, K. D. (2007) HR's role in building a sustainable enterprise: insights from some of the world's best companies. People and Strategy, 30(1), 10-11.

Wright, P. M. (1998) Introduction: strategic human resource management research in the 21st century. Human Resource Management Review, 8(3), 187-191.

Data da submissão: 20/01/2014

Data da publicação: 30/04/2014

\footnotetext{
${ }^{\text {i }}$ A Matriz de Materialidade é uma metodologia sugerida pelo Global Reporting Initiative - GRI. A gestão da sustentabilidade da Natura envolve esta Matriz e em 2010, temas como Amazônia, biodiversidade, gases de efeito estufa, educação, impactos dos produtos e qualidade das relações foram considerados prioritários.

ii $\mathrm{O}$ EBTIDA é um indicador financeiro baseado no fluxo de caixa operacional de uma empresa antes do cálculo do imposto de renda.
} 